\title{
S5ynthesis
}

International Scientific Conference of IT and Business-Related Research

\section{KRITERIJUMI ZA EVALUACIJU SIMULATORA RAČUNARSKIH MREŽA}

\author{
EVALUATION CRITERIA FOR COMPUTER NETWORK SIMULATORS
}

\author{
Zoran Jovanović ${ }^{1}$, Aleksandar Jevremović 2 , Nenad Jovanović ${ }^{3}$ \\ ${ }^{1}$ Visoka poslovna škola strukovnih studija, Blace, Srbija \\ ${ }^{2}$ Univerzitet Singidunum, Danijelova 32, Beograd, Srbija \\ ${ }^{3}$ Fakultet tehničkih nauka u Kosovskoj Mitrovici, Srbija
}

\begin{abstract}
Apstrakt:
Tradicionalni obrazovni sistem, koji se prevashodno zasniva na teorijskom učenju, ne daje dobre rezultate kada je u pitanju obrazovanje studenata za rešavanje praktičnih problema. Simulacije i simulacioni sistemi predstavljaju važnu podršku za praktične aspekte nastave i pružaju dobar način za povezivanje i razumevanje apstraknih koncepata koji su obrađeni na predavanju. U ovom radu su definisani kriterijumi koji mogu da se koriste u procesu evaluacije sumulatora računarskih mreža pogodnih za upotrebu u obrazovne svrhe.
\end{abstract}

\section{Ključne reči:}

računarske mreže, mrežni simulatori, edukacija, elektronsko učenje.

\section{Abstract:}

The traditional education system, which is primarily based on the theoretical models of teaching, does not offer favourable results in terms of providing students with adequate training that would enable them to solve practical issues. Simulations and simulation systems are of vital importance as they provide support to practical aspects of the teaching process and a good way to connect to and gain a better understanding of the abstract concepts covered in lectures. This paper defines the criteria that can be used in the evaluation process of computer network simulators suitable for educational purposes.

\section{Key words:}

computer networks, network simulators, training, e-learning.

\section{Zahvalnica:}

Ovaj rad je podržan od strane Ministarstva prosvete i nauke Republike Srbije (projekat III44006).

\section{UVOD}

Računarske mreže predstavljaju veoma važnu oblast u računarstvu i informatici, pa kursevi u ovoj oblasti moraju da ostvare više ciljeva. Primarni cilj je da moraju da obezbede pregled osnovnih koncepata računarskih mreža i da daju uvid u rad tipične računarske mreže. Osim toga, oni bi trebalo da naglase sva važna pitanja u računarskim mrežama sa kojima se inženjeri suočavaju u praksi. Nastava iz oblasti računarskih mreža se nalazi u preporukama vodećih međunarodnih organizacija kao bitan deo kurseva računarskih nauka. Studenti se susreću sa konceptima računarskih mreža na predavanjima i vežbama i od njih se traži da razumeju apstraktne pojmove o radu ovih sistema. Simulatori računarskih mreža omogućavaju na jednostavan način razumevanje tih apstraktnih pojmova.

$\mathrm{U}$ ovom radu autori su uspostavili skup relavantinih kriterijuma koji omogućavaju procenu sumulatora računarskih mreža koji mogu da se koriste u edukacione svrhe. Ovi kriterijumi mogu da se svrstaju u grupu koja je nazvana kriterijumi pokrivenosti (coverage criteria). Kriterijumi pokrivenosti služe za procenu koje teme iz računarskih mreža podržavaju pojedini simulatori.

Razmatrani su i drugi kriterijumi, kao što su lakoća upotrebe, uticaj na učinak učenja, uticaj na razumevanje pređenog gradiva, transparentnost distrbuiranih simulatora, prikrivanje informacija, ali uključivanje ovih kriterijuma zahteva stvarnu upotrebu simulatora, što je nepraktično, pa su kriterijumi ograničeni samo na one koji se mogu analizirati na osnovu informacija dostupnih iz literature.

\section{KRITERIJUMI EVALUACIJE}

Kriterijumi pokrivenosti tema su ustanovljeni korišćenjem IEEE Computer Engineering (2004) smernica nastavnog plana i programa za računarske nauke (Curriculum, 2004). Ovaj dokument predstavlja finalni izveštaj zajedničke radne grupe za nastavni plan i program računarstva - poduhvat je delo SIGITE (Special Interest Group on Information Technology Education) u sklopu ACM (Association for Computing Machinery), ACM i IEEE udruženja - za programe u računarskom inženjeringu i definisanja široke oblasti koje se mogu primeniti na sve studijske programe iz oblasti računarskih nauka. Računarske mreže su jedna od ovih oblasti koja podrazumeva sledeće nastavne teme (Curriculum, 2004):

1. Pregled,

2. Komunikacija i mrežne arhitekture,

3. Komunikacije i mrežni protokoli,

4. LAN i WAN mreže,

5. Klijent-server,

6. Bezbednost i integritet podataka,

7. Bežično i mobilno računarstvo.

\section{EVALUACIJA SIMULATORA}

Teme, koje su izabrane kao osnovni kriterijumi, date su sa detaljnim opisima u tabeli 1. Prva tema se ne uzima u obzir. U tabeli 1 prikazani su rezultati evaluacije, pri čemu su u pro- 
cesu evaluacije uzeti u obzir sledeći simulatori: GTNetS (Riley, 2003), GloMoSim (Bajaj, 1999), KivaNS (Candelas, 2009), CNET (CNET simulator), NetSim (Veith, 1999), Nessi (Vernez, 2006) i WnetSim (Jovanovic, 2009; Jovanovic, 2012).
Komparativna analiza performansi ovih simulatora nije objavljena u velikom broju radova, a već postojeći radovi obično uključuju ograničen skup eksperimenata sa jednostavnim scenarijima simulacije.

\begin{tabular}{|c|c|c|c|c|c|c|c|c|}
\hline Oblasti & Nastavne teme & 岕 & 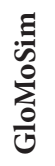 & $\underset{Z}{\tilde{N}}$ & 空 & $\begin{array}{l}\Xi \\
\text { Z } \\
\text { Z }\end{array}$ & $\begin{array}{l}\bar{n} \\
\tilde{n} \\
\bar{y}\end{array}$ & 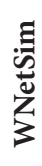 \\
\hline \multirow{4}{*}{$\begin{array}{l}\text { Komunikacija i } \\
\text { mrežne arhitekture }\end{array}$} & Konfigurisanje mreže (point-to-point, multipoint) & + & + & + & + & + & - & + \\
\hline & Mrežni uređaji: ripiteri, mostovi, svičevi, ruteri & + & + & + & + & + & - & + \\
\hline & Mrežne topologije (zvezda, prsten, magistrala, rešetka) & + & - & + & + & + & + & + \\
\hline & Servisa sa i bez uspostavljanja veza & + & - & - & + & + & - & + \\
\hline \multirow{4}{*}{$\begin{array}{l}\text { Komunikacije i } \\
\text { mrežni protokoli }\end{array}$} & Mrežni protokoli & + & + & + & + & + & + & + \\
\hline & Stek protokola $(\mathrm{TCP} / \mathrm{IP})$ & + & + & + & - & + & + & + \\
\hline & Koncepti fizičkog sloja; koncepti sloja veze; rutiranje & + & - & + & + & + & + & + \\
\hline & Mrežni standardi & - & - & + & - & + & - & + \\
\hline \multirow{7}{*}{ LAN i WAN mreže } & LAN topologije & + & + & + & + & + & + & + \\
\hline & LAN tehnologije (Ethernet, token Ring, Gigabit Ethernet) & + & + & + & + & + & + & + \\
\hline & Detekcija i korekcija grešaka & + & - & + & + & + & + & + \\
\hline & Carrier sense multiple access (CSMA) & + & + & - & + & + & + & - \\
\hline & Velike mreže & + & - & - & - & + & - & + \\
\hline & Mreže sa komutacijom kola i komutacijom paketa & + & - & - & - & + & - & + \\
\hline & Protokoli (adresiranje, kontrola zagušenja, virtualne veze, quality of service) & + & + & + & + & + & + & + \\
\hline \multirow{3}{*}{ Klijent-server } & Web tehnologije & - & - & - & - & - & - & - \\
\hline & Karakteristike web servera & + & - & - & - & - & - & - \\
\hline & Podrška za kreiranje web sajtova & - & - & - & - & - & - & - \\
\hline \multirow{7}{*}{$\begin{array}{l}\text { Bezbednost i in- } \\
\text { tegritet podataka }\end{array}$} & Osnovi bezbednosti u mreži; kriptografija & - & - & - & + & + & - & - \\
\hline & Enkripcija i privatnost & - & - & - & + & + & - & - \\
\hline & Protokoli autentifikacije & - & & - & + & + & - & - \\
\hline & Filtriranje paketa & - & - & - & + & + & - & - \\
\hline & Firewalls & - & 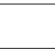 & - & + & - & - & - \\
\hline & Virtuelne privatne mreže & + & - & - & + & + & - & - \\
\hline & Bezbednost na transportnom sloju & - & + & - & + & + & - & - \\
\hline \multirow{11}{*}{$\begin{array}{l}\text { Bežično i mobilno } \\
\text { računarstvo }\end{array}$} & Pregled, evaluacija, kompatabilnost bežičnih standarda & - & - & - & - & - & - & - \\
\hline & Specijalni problemi bečičnih mreća i mobilnog računarstva & - & + & - & + & - & - & - \\
\hline & Bežične lokalne mreže i mreže zasnovane na satelitima & - & + & - & + & - & - & - \\
\hline & Mobilni Internet protokol & - & + & - & & - & - & - \\
\hline & Mobilne adaptacije & - & - & - & & - & - & - \\
\hline & Prošireni klijent-server model za prilagođavanje mobilnosti & - & + & - & + & - & - & - \\
\hline & Mobilni pristup podacima & - & + & - & & - & - & - \\
\hline & Softverski paketi za podršku bežičnom i mobilnom računarstvu & - & + & - & - & - & - & - \\
\hline & Uloga srednjeg sloja i alati za podršku & - & - & - & - & - & - & - \\
\hline & Problemi sa performansama & - & - & - & - & - & - & - \\
\hline & Nove tehnologije & - & - & - & - & - & - & - \\
\hline
\end{tabular}

Tabela 1. Osnovne teme koje se koriste kao kriterijumi pokrivenosti

\begin{tabular}{|l|c|c|}
\hline Oblasti & h & $\%$ \\
\hline Komunikacija i mrežne arhitekture & 3 & 15 \\
\hline Komunikacije i mrežni protokoli & 4 & 20 \\
\hline LAN i WAN mreže & 4 & 20 \\
\hline Klijent-server & 3 & 15 \\
\hline Bezbednost i integritet podataka & 4 & 20 \\
\hline Bežično i mobilno računarstvo & 2 & 10 \\
\hline
\end{tabular}

Procena simulatora prema kriterijumima koji su zasnovani prema smernicama Computer Engineering (2004) nastavnog plana i programa za studente računarskih nauka je predstavljena u tabeli 1. Oznaka „+" znači da simulator ima funkcionalnost neophodnu za pokrivanje nastavnog materijala u određenoj oblasti računarske mreže, dok oznaka „,-" znači da simulator nema određenu funkcionalnost neophodnu za pokrivanje nastavnog materijala u datoj oblasti.

$\mathrm{Na}$ osnovu rezultata vrednovanja mogućnosti upotrebe simulatora za pokrivanje navedenih tema, u tabeli 2 je dat udeo pojedinih oblasti, procentualno u odnosu na ukupan broj časova nastave (Curriculum, 2004).

$\mathrm{U}$ tabeli 3 sumirani su rezultati upoređivanja simulatora

Rezultati upoređivanja simulatora prema pokrivenosti tema su predstavljeni u tabelama 1, 2 i 3 . prema pokrivenosti oblasti, u odnosu na udeo pojedinih oblasti u ukupnom broju časova. 


\begin{tabular}{|c|c|c|c|c|c|c|c|}
\hline Oblasti & 芯 & 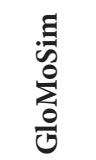 & 资 & 离 & $\begin{array}{l}\text { : } \\
\text { zै } \\
\text { ż }\end{array}$ & $\begin{array}{l}\bar{n} \\
\text { ज1 } \\
\text { Z }\end{array}$ & 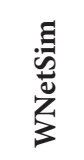 \\
\hline Komunikacija i mrežne arhitekture & 15.00 & 7.50 & 11.25 & 15.00 & 15.00 & 3.75 & 15.00 \\
\hline Komunikacije i mrežni protokoli & 15.00 & 10.00 & 20.00 & 10.00 & 20.00 & 15.00 & 20.00 \\
\hline LAN i WAN mreže & 20.00 & 11.43 & 11.43 & 14.29 & 20.00 & 14.29 & 17.14 \\
\hline Klijent-server & 5.00 & 0.00 & 0.00 & 0.00 & 0.00 & 0.00 & 0.00 \\
\hline Bezbednost i integritet podataka & 2.86 & 2.86 & 0.00 & 20.00 & 17.14 & 0.00 & 0.00 \\
\hline Bežično i mobilno računarstvo & 0.00 & 5.45 & 0.00 & 2.73 & 0.00 & 0.00 & 0.00 \\
\hline Ukupna pokrivenost & 57.86 & 37.24 & 42.68 & 62.01 & 72.14 & 33.04 & 52.14 \\
\hline
\end{tabular}

Tabela 3. Rezultati upoređivanja simulatora prema pokrivenosti oblasti

\section{ZAKLJUČAK}

Na osnovu kvantitativnih rezultata prikazanih u tabeli 3 izvedeni zaključci su dati u nastavku.

Teme Komunikacija i mrežne arhitekture su pokrivene u velikoj meri u gotovo svim simulatorima. Izuzetak su simulatori, kao što je Nessi, koji su razvijeni za specijalizovane potrebe. Dok se drugi simulatori fokusiraju na minimiziranje vremena simulacije, nessi pokušava da minimizuje vreme razvoja i teškoća u implementaciji novih simulacionih modela. Prednost Nessi-ja je ta što se simulacioni modeli mogu razviti za mnogo kraće vreme nego što je to potrebno sa drugim simulatorima. Nessi omogućava studentima da kreiraju ili modifikuju modele mrežnih protokola sa minimalnim opterećenjem i na taj način je savršeno pogodan za povezivanje mrežnih vežbi ili semestralnih projekata.

Teme iz oblasti $L A N i$ WAN mreža su pokrivene kod gotovo svih simulatora.

Teme iz oblasti Komunikacije i mrežni protokoli su najbolje pokrivene simulatorima KivaNS, NetSim i WNetSim.

Uglavnom, KivaNS sa dosta detalja realizuje sledeće protokole: Ethernet za IP, PPP, IP i ARP. Takođe, sprovodi IP rutiranje i fragmentaciju. IP usmeravanje se može konfigurisati na sličan način kao u realnom OS. Osim toga, on takođe obrađuje Ethernet topologije, kao i Spanning Tree algoritma (pojednostavljeni 802.1d). Fizički mediji mogu simulirati greške u frejmovima, dok link i mrežni protokoli rade konsenkventno.

Teme iz oblast bezbednosti i integriteta podataka imaju veoma dobru pokrivenost sa cnet i NetSim simulatorima.

Cnet pruža mnoge od osnovnih mogućnosti za niže nivoe umrežavanja, kao što su prenos podataka i prijem, verovatnoća uvođenja grešaka, precizan tajming i statističke funkcije, raznovrsnost NIC tipova i programirajuću mobilnost čvora, ali sve te karakteristike ne omogućava u svojoj standardnoj distribuciji.

Teme u oblasti bežičnog i mobilnog računarstva i klijentserver računarstva su slabo podržane od strane gotovo svih simulatora. Izuzetak je GloMoSim simulator koji je razvijen za specijalizovane potrebe. Razlog za to je što se većina analiziranih simulatora uglavnom koncentriše na teme vezane za osnovne komponente računarskih mreža.

Postoje simulatori sa generalno nižom pokrivenosti tema, ali sa visokim nivoom pokrivenosti tema koje se tiču određenih, konkretnih jedinica, na primer Cnet i NetSim pokrivaju oblasti bezbednosti i integriteta podataka. Ova vrsta informacija je mnogo važnija od ukupne pokrivenosti ograničenih na određene nastavne jedinice.

Rezultat procene pokazuje da ne postoji jedinstven simulator koji pokriva sve teme. Rezultat je posledica činjenice da je oblast računarskih mreža raznovrsna i da uključuje veliki broj tema, pa bi razvoj simulatora koji pokriva sve teme kao rezultat dao sistem koji bi bio veoma glomazan i nepraktičan za korišćenje.

Najbolja ukupna pokrivenost tema se postiže sa simulatorima NetSim (72,14\%). Većina simulatora postiže više od 50,00\% pokrivenosti. Ostali simulatori postižu oko $30.00 \%$ pokrivenosti.

$\mathrm{Na}$ kraju vredi napomenuti da procenat pokrivenosti ne daje informacije o prednosti korišćenja pojedinih simulatora, već samo o broju obuhvaćenih tema, odnosno o temama iz oblasti računarskih mreža koje se lako mogu pokriti pomoću datog simulatora.

\section{LITERATURA}

Bajaj, L., et al. (1999). Glomosim: A scalable network simulation environment. UCLA Computer Science Department Technical Report 990027 (1999): 213.

Candelas Herías, F. A., \& Gil Vázquez, P. (2009). Practical experiments with KivaNS: A virtual laboratory for simulating IP routing in computer networks subjects. Research, Reflections and Innovations in Integrating ICT in Education. Available from: http://rua.ua.es/dspace/bitstream/10045/14051/1/ mICTE_KIVANS1414-1418.pdf

CNET simulator: An introduction to the cnet network simulator. Available from: http://www.csse.uwa.edu.au/cnet/introduction.html

IEEE. (2004). Computer Engineering 2004 Curriculum Guidelines for Undergraduate Degree Programs in Computer Engineering. Available from: http://www.acm.org/education/curric_vols/

Jovanovic, N., Popovic, R., Markovic, S., \& Jovanovic, Z. (2012). Web laboratory for computer network. Computer Applications in Engineering Education, 20(3), 493-502. DOI: 10.1002/cae.20417

Jovanovic, N., Popovic, R., \& Jovanovic, Z. (2009). WNetSim: a web-based computer network simulator. International Journal of Electrical Engineering Education, 46(4), 383-396.

Riley, G. F. (2003). The georgia tech network simulator. Proceedings of the ACM SIGCOMM workshop on Models, methods and tools for reproducible network research. ACM, 2003.

Veith, T. L., Kobza, J. E., \& Koelling, C. P. (1999). Netsim: Java ${ }^{\mathrm{Tm}}$ based simulation for the World Wide Web. Computers of operations research, 26(6), 607-621. DOI:10.1016/S03050548(98)00039-2

Vernez, J., Jürgen, E., \& Stephan, R. (2006). Nessi: a python network simulator for fast protocol development. ComputerAided Modeling, Analysis and Design of Communication Links and Networks, 2006 11th International Workshop on. IEEE. DOI: 10.1109/CAMAD.2006.1649720 